\title{
Aplicaciones de la técnica de aproximación facial forense en la identificación humana individual.
}

\author{
Usefulness of technique of forensic facial approximation in \\ the individual human identification.
}

\section{F. Serrulla1 y M. Gómez²}

\begin{abstract}
RESUMEN
OBJETIVOS: Valorar el interés y la utilidad de la técnica de aproximación facial forense en la identificación humana individual. MATERIAL: Tres esqueletos hallados en contexto arqueológico de cronología situada entre los siglos III y VII. Técnica aplicada sobre restos humanos carbonizados sin identificación. MÉTODOS: Elaboración del croquis antropológico mediante fotografía métrica, método Gerasimov (1955) de reconstrucción del perfil nasal, técnica de Stephan de posicionamiento de los ojos y boca y estimación de las profundidades de partes blandas a partir de la base de datos de De Greef (2006). Obtención de un prototipo de cráneo en polirresina por estereolitografía a partir de las imágenes DICOM obtenidas del escaneado convencional del cráneo. Trabajo artístico en arcilla y pasta de modelar con aplicaciones de pinturas diversas para realizar una escultura en 3D. Las primeras fases de la técnica se han aplicado al caso de la aparición de un cadáver carbonizado sin muestra indubitada de ADN. Generamos varias imágenes en 2D para su distribución por los medios de comunicación. RESULTADOS: La técnica de aproximación facial nos ha permitido acercarnos a conocer el rostro de algunas personas que habitaron A Coruña hace 1600 años. Su aplicación con fines forenses nos ha permitido excluir dos personas desaparecidas pero no ha permitido por el momento identificar la persona fallecida. CONCLUSIONES: Creemos que la técnica de aproximación facial simplificada para imágenes 2D ha demostrado ser una herramienta útil para la identificación humana individual en casos seleccionados.
\end{abstract}

Palabras clave: Aproximación Facial, Forense, Identificación.

Cuad Med Forense 2008; 14(53-54):291-307

\section{ABSTRACT}

AIMS: To assess interest and usefulness of technique of forensic facial approximation in the individual human identification. MATERIAL: From three skeletons found in archaeological context with chronology between III to VII century. We have applicated this technique in a case of human remains burned. METHODS: We have made the anthropological sketch with metric photography, nasal reconstruction profile with Gerasimov's method (1955), Stephan's method of placing eyes and mouth and estimation of dephts of soft-tissues by the database of De Greef (2006). By stereolithography we have made a prototype in polyresin to start from conventional scanned to skull. Artistic work in modeling clay and modeling paste with several paints to made a sculpture in 3D. Some phases of this technique have been applicated in a case of a burned man without undoubted sample of ADN. We have made several draws in 2D and we have sended this draws to distribution in some media. RESULTS: With this technique of forensic facial approximation we have got to lend to know the face of people who lived in A Coruña in III to VII centurys. The application of this technique with forensic aims we have got to exclude two people. Unluckily today we haven't got to identificate the man burned. CONCLUSIONS: We think what the technique of forensic facial approximation simplified with 2D draws is a useful tool to human identification in selected cases.

Key words: Facial Approximation, Forensic, Identification.

Trabajo subvencionado por el Excmo. Ayuntamiento de La Coruña

Correspondencia: Dr. Fernando Serrulla. Hospital Fundación Pública Verín. Carretera de Laza s/n. 32600 Verín (Ourense). Tfno-Fax: 00.34.988.599021. E-mail: fernandoserrullarech@hotmail.com

${ }^{1}$ Médico Forense. Especialista en Antropología Forense. Unidad de Antropología Forense. IMELGA.

2 Artista Forense. Escultora Experta en Restauración de Obras de Arte. Unidad de Antropología Forense. IMELGA. 


\section{INTRODUCCIÓN Y ANTECEDENTES HISTÓRICOS:}

La Unidad de Antropología Forense (UAF) es un laboratorio del Instituto de Medicina Legal de Galicia creado en el año 2006 encargado del estudio de restos óseos y otros restos humanos, de la protocolización médico forense en sucesos de múltiples víctimas, del auxilio médico forense en los casos de levantamientos de cadáveres complejos, así como de la realización de actividades de investigación y docencia.

En relación con esta última función de la UAF el Excmo. Ayuntamiento de A Coruña nos planteó la posibilidad de 'poner rostro' a los restos humanos más antiguos conservados en la ciudad. El octavo centenario de la ciudad celebrado en el pasado año 2008 ha sido el motivo de la realización de una exposición que ha recibido el nombre de 'Rostros Brigantium' y que ha recreado el proceso arqueológico y el antropológico forense y también ha permitido acercarnos a conocer el rostro de aquellos pobladores del asentamiento romano llamado Brigantium situado en lo que hoy es el centro de la ciudad de A Coruña.

Las llamadas técnicas de reconstrucción facial tienen su origen histórico en el siglo XIX con los trabajos de Schaaufhausen (1875, I883) quien publica Sobre la máscara mortuoria de Shakespeare y La Cabeza de Raphael. Otros autores en fechas posteriores trataron también de confirmar si determinados restos óseos se correspondían o no con los retratos de célebres personajes (Kant, Haydin y Bach) [I].

Pero la época científica de la reconstrucción facial comienza con los interesantes trabajos del anatomista ruso Mihail Gerasimov cuyo origen es el texto Vosstanovlenie lica po cerepu ( $\mathrm{La}$ reconstrucción de la cara desde el cráneo) [2, 3]. Este autor desde la paleontología y la paleoantropología plantea por primera vez la aplicación de metodología cientíica en la reconstrucción de rostros. Establece, entre otras muchas cosas, las bases anatómicas de la técnica de reconstrucción facial fundamentada en la reconstrucción de grupos musculares cráneo-faciales.

Habría que esperar hasta 1962 para que éstas técnicas de reconstrucción facial empezaran a tener aplicación en el ámbito forense con el método desarrollado por Krogman WM basado en los denominados puntos cráneométricos [4]. Los trabajos de Krogman fueron mejorados en la segunda edición de éste clásico tratado de Antropología Física [5] y aplicados por otros muchos antropólogos forenses como Snow C. (1970) y Ubelaker DH (1992). Este último autor es uno de los primeros en incluir en su metodología la tecnología informática como una herramienta de ayuda a la reconstrucción facial [6, 7].

Posiblemente al amparo del desarrollo informático que aconteció en la década de los noventa muchos autores en Europa, en EEUU y en otras zonas del mundo comienzan a publicar multitud de trabajos relacionados con la reconstrucción facial basados en nuevas técnicas de imagen tanto desde la óptica de la Medicina Legal y Forense como desde la Antropología Física. Fruto de todo ello se funda en 1992 la International Association of Craneofacial Identification. En Europa el interés por la reconstrucción facial crece enormemente destacando autores como Quatrehomme G [8], Rinn C, Wilkinson C (Método Manchester) [9] y De Greef [10].

Creemos que en el campo de la reconstrucción (aproximación) facial sobre todo destacan las aportaciones que ha hecho y sigue haciendo Carl N. Stephan cuya página web es una cita ineludible para todos los estudiosos de esta apasionante área de la identificación humana [ I I]. Stephan ha mostrado su discrepancia respecto a la utilización del término 'reconstrucción' y es uno de los defensores de emplear en su lugar el término 'aproximación' dadas las imprecisiones que la técnica tiene para la identificación humana. Destacaríamos muchos trabajos de éste autor, pero como muestra creemos suficiente con mencionar el trabajo publicado en el año 2006 [I2]. 
Para terminar creemos necesario decir que como se puede deducir de lo anterior, en la actualidad existen dos grandes métodos de aproximación facial. El que podríamos llamar método artístico que nos permite obtener directamente la reproducción física del rostro, y el método asistido por ordenador que nos permite obtener una imagen digitalizada habitualmente mostrada bajo un software 3D. Sobre las ventajas y desventajas de cada uno de los métodos hablaremos más adelante. Nosotros hemos decidido utilizar el método artístico. Esta decisión se ha basado fundamentalmente en criterios de disponibilidad de medios.

Con estos antecedentes la UAF se comprometió a estudiar la viabilidad del proyecto del Ayuntamiento de Coruña y decidió acometer el trabajo con el objetivo añadido de buscar aplicaciones útiles a la técnica de aproximación facial en el ámbito estrictamente forense de la identificación humana. El objetivo general de éste trabajo ha sido pues aprender una técnica nueva para conocer sus utilidades y limitaciones. Redactar esta síntesis que ahora presentamos no tiene más objetivo que comunicar nuestra experiencia alejados en todo caso de cualquier pretensión educativa sistematizada.

\section{MATERIAL Y MÉTODOS:}

\section{I.- MATERIAL:}

Partimos del material esquelético que nos fue cedido por el Museo Arqueológico de Coruña. Se trataba de tres esqueletos incompletos exhumados en distintos periodos de tiempo, pero localizados todos en la misma zona de la ciudad de A Coruña: la calle Real. Los esqueletos, siglados como MAC-I08, MAC-1 10 y MAC-44I4, fueron situados cronológicamente entre los siglos III y VII. Los esqueletos fueron seleccionados entre los esqueletos custodiados en el museo que conservaban mejor los huesos faciales. MAC- 108 y MAC-I I 0 son esqueletos exhumados en diferentes excavaciones de los años 70 y MAC-44I 4 pertenece a una intervención arqueológica del año 2003. MAC- 108 se conservaba expuesto en el museo pegado con pegamentos y alambres a una tabla de madera y blanqueado por técnica no conocida. MAC-I I 0 también se hallaba blanqueado y se remitió a nuestro laboratorio mezclado con algunos otros restos óseos. MAC-44 I 4 no habia sido tratado y mostraba un esqueleto poscraneal en mal estado de conservación (ver Figs. I,2,3).
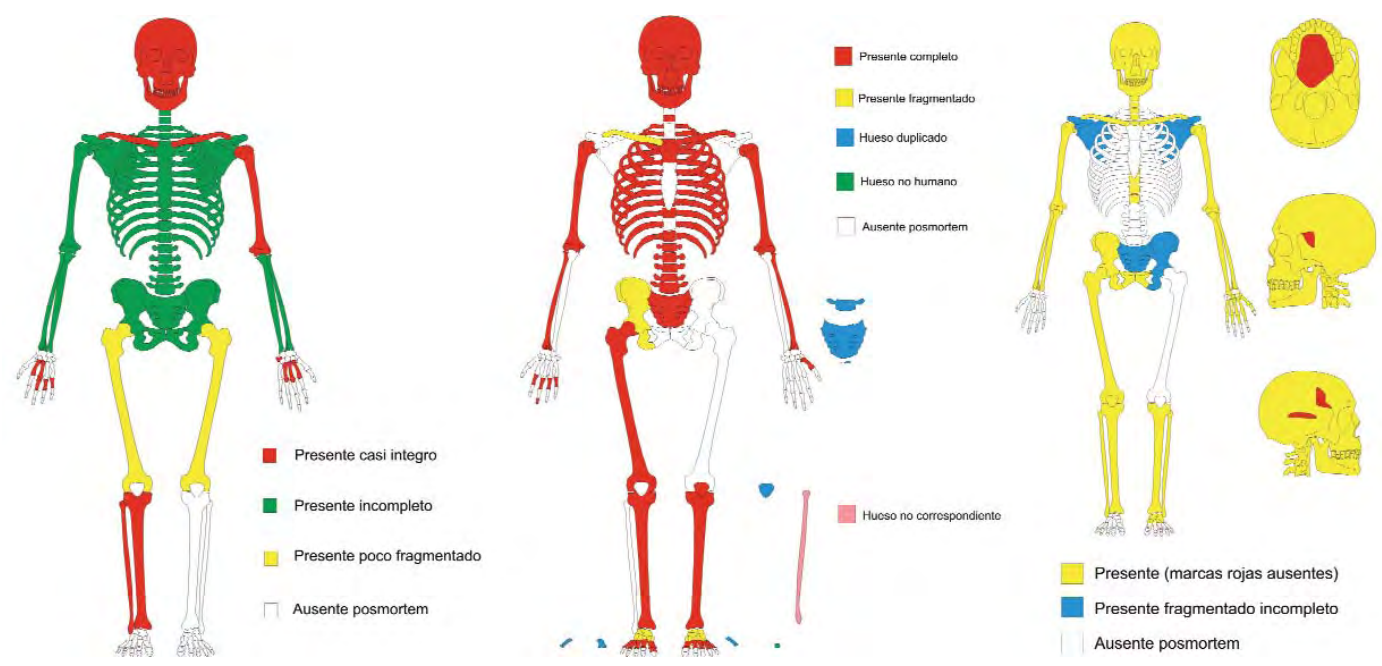

Figuras 1, 2 y 3: Representan de izquierda a derecha el inventario esquelético de MAC-4414, MAC-110 Y MAC-108 con sus respectivas leyendas. 
Por otro lado parte de la técnica de aproximación facial que hemos realizado en estos esqueletos ha sido aplicada al caso del cadáver casi carbonizado de una persona que nos fue remitido a la UAF para su estudio (Fig. 4). Se trataba de un cadáver que apareció en las afueras de una capital gallega en el interior de una caseta abandonada y parcialmente quemada y que -según la policía- era habitualmente usada por toxicómanos e indigentes. No se había denunciado la desaparición de ninguna persona en la ciudad y nadie reclamó el cadáver.

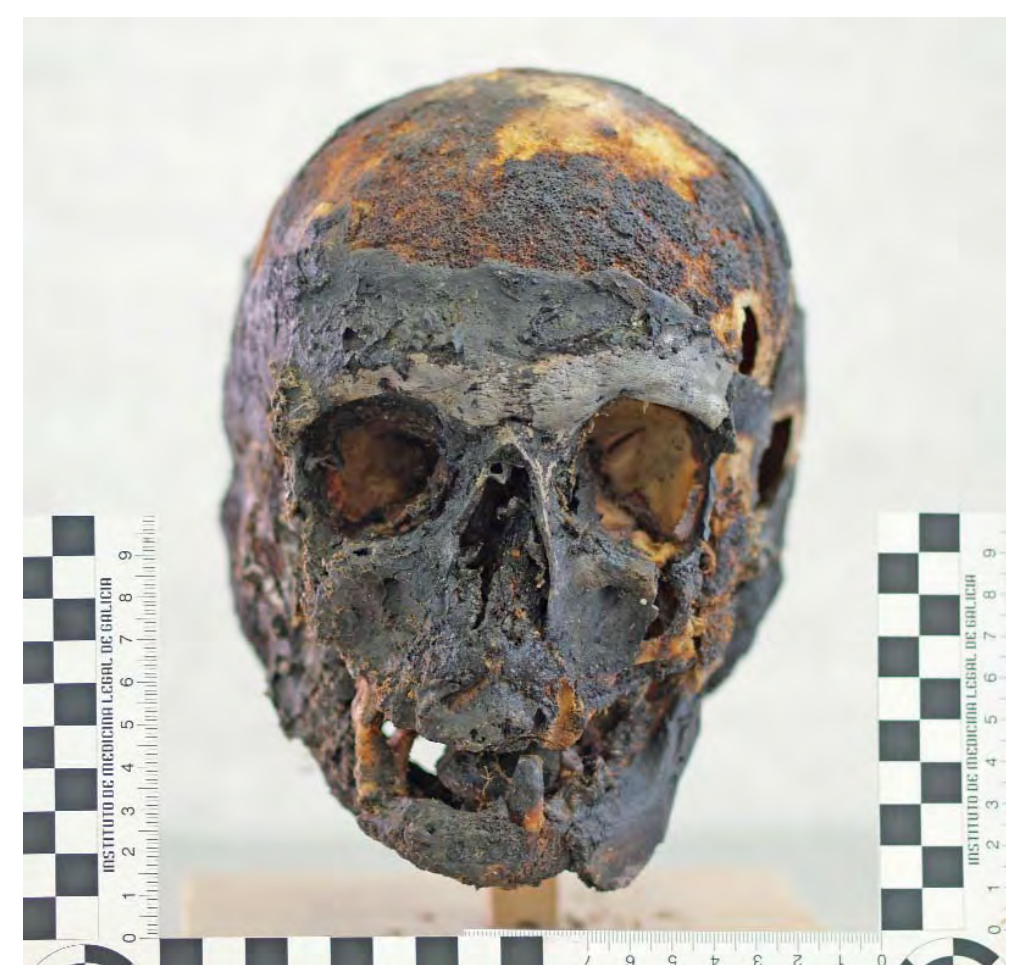

Figura 4. Cabeza carbonizada sobre la que se aplicó la técnica de aproximación facial.

\section{2.- MÉTODOS:}

En cuanto a la aproximación facial podríamos sistematizar el método en las siguientes fases de trabajo:

\section{I.- Fase antropológico forense:}

2. I. I.- Identificación reconstructiva: Los restos óseos han sido mediados con calibre convencional, compás de espesor, tabla osteométrica, mandibulómetro, cinta métrica y goniómetro. Han sido observados con luz natural, artificial y ultravioleta (lámpara de Wood), bajo lupa y al estereomicrocopio a 45x. Han sido fotografiados con Cámara Digital Nikon Coolpix 4300 (4 Mp) y Olympus E-330 (7.6 Mp). Se han empleado estereomicrocopio Olympus SZXIO con adaptador fotográfico.

Hemos empleado la última versión actualizada de FORDISC 3.0 (Version 3.0.28I, Universidad de Tenessee, Noviembre 2007).

Según los métodos antes mencionados se obtienen todos los datos de interés identificativo: sexo, edad, origen ancestral y talla. Se realiza estudio relativo a la osteopatología detectada y se 
emiten las correspondientes hipótesis de causas y circunstancias de la muerte. Todos estos datos son esenciales en las fases siguientes.

2. I.2.- Elaboración del croquis antropológico: El croquis antropológico es el elemento fundamental del trabajo antropológico forense en aproximación facial. Sintetiza el estudio antropológico que servirá de base a la artista forense. Por ello es esencial mantener un exquisito rigor en su elaboración.

Empezamos obteniendo fotografías métricas del cráneo en plano de Franckfurt de frente y de perfil (derecho). Es necesario obtener la máxima precisión posible en la técnica fotográfica (posición adecuadamente centrada de la cámara, profundidad de campo óptima y condiciones optimas de iluminación fundamentalmente). Obtenemos así imágenes digitales con testigo métrico (Figs. 5 y 6 ).

A continuación estas fotografías se imprimen a escala l:| en papel convencional. Seguidamente y utilizando papel cebolla se calcan los perfiles necesarios tanto de la visión frontal como del perfil derecho.

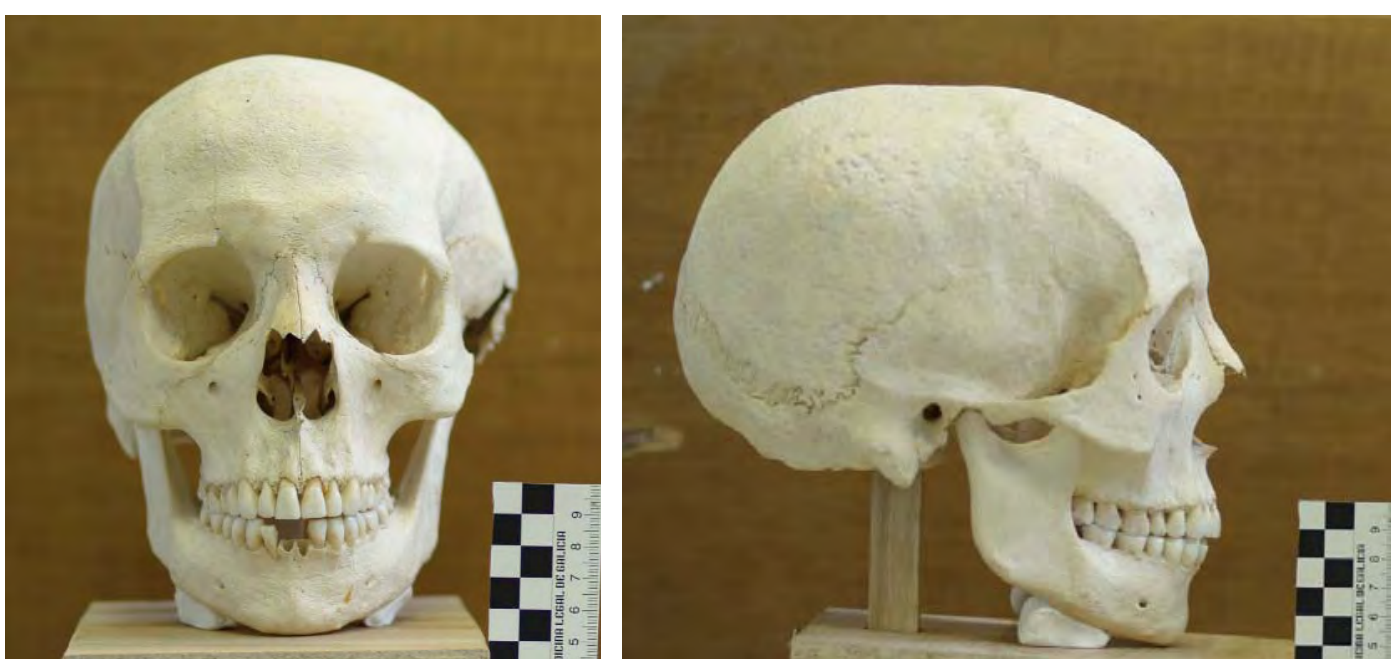

Figuras 5 y 6 . Fotografias del frontal y perfil derecho del craneo MAC-110.

Sobre las líneas calcadas de ambos perfiles trabajamos en lo siguiente:

- Posicionamiento de los ojos: Muchos estudios afirman que el centro del iris se halla muy próximo al centro de la órbita. Stephan (2008) y otros autores han demostrado por estudios anatómicos que esto no es del todo cierto. Al parecer el centro del iris se halla en un gran número de casos discretamente en posición supero-externa. Determinando geométricamente el centro de la órbita posicionamos el centro del iris a I,2 mm por arriba y a I,7 mm en posición externa de aquel centro $[13,14$, I 5$]$. Los mismos fundamentos bibliográficos hemos seguido en el caso de la posición del ojo en el perfil derecho.

- Reconstrucción de la nariz: Un interesante y reciente trabajo de Rynn C y Wilkinson C (2006) [9] (Universidad de Manchester) ha comparado 6 métodos de reconstrucción del perfil de la nariz de diferentes autores: Krogman-Iscan (1986), Gerasimov (1955), Prokopec-Ubelaker (2002), Macho (1986), George (1987) y Stephan (2003). Rynn y Wilkinson concluyen que el mejor método de reconstrucción del perfil nasal es el deno- 
minado 'De las dos tangentes' ideado hace más de 50 años por Gerasimov. Este método se basa en la idea de Gerasimov de considerar las partes blandas de la nariz como una continuación natural de sus partes óseas. Según Gerasimov para obtener la punta de la nariz es necesario trazar dos líneas: una que seguiría la última inclinación de los huesos propios y otra que formaría la proyección de la espina nasal. Nosotros hemos seguido este criterio en nuestro trabajo de aproximación facial.

- Posicionamiento de la boca: Sobre el particular se han publicado varios trabajos. Nosotros hemos seguido el criterio que han planteado Stephan CN y Henneberg M (2003) [ I 6]. Para estos autores la creencia de que los extremos de la boca coinciden con la perpendicular del centro de ambos iris o de la tangente interna de ambos iris no es del todo correcta. Stephan y Henneberg acuerdan que la anchura de la boca debe estimarse considerando que la distancia intercanina es el $75 \%$ del total de ésta anchura. Con este criterio hemos trabajado en nuestros casos.

- Determinación de la profundidad de las partes blandas: En aproximación facial la determinación de la profundidad de las partes blandas es la cuestión fundamental a resolver. Diversos autores han dedicado mucho tiempo de sus investigaciones a este tema. Quizás uno de los trabajos más completos es la investigación llevada a cabo por De Greef et al. (2005)[17]. Este trabajo a diferencia de otros muchos ha elaborado una base de datos muy completa a partir de la medición mediante ecografia de 52 puntos craneofaciales en 967 personas vivas de origen ancestral caucásico, clasificados por grupos de edad, sexo e índice de masa corporal (IMC). Determinado por lo tanto el sexo, el origen ancestral y la edad del esqueleto nosotros podemos buscar en la base de datos los valores que le corresponden estimando el IMC por los datos paleopatológicos que hayamos podido observar. Todos los valores (con décimas de milímetro) que proporciona el trabajo de De Greef et al se anotan en el croquis antropológico (Fig. 7).

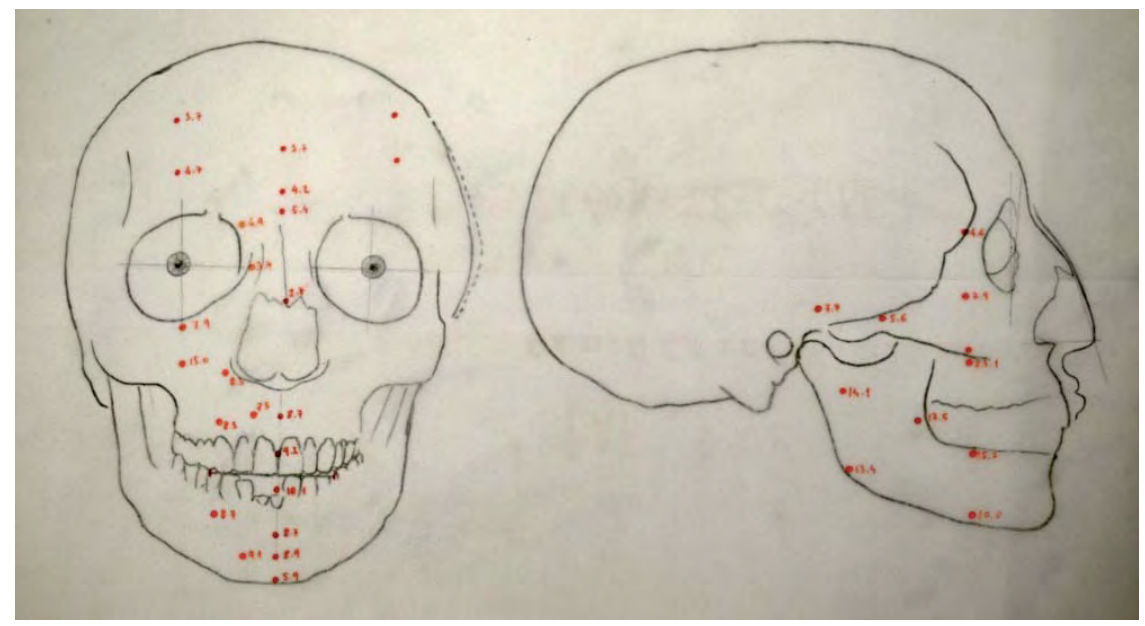

Figura 7. Croquis antropológico obtenido del esqueleto MAC 110.

Con el registro de las profundidades de partes blandas hemos terminado el croquis antropológico que podremos pasar a la artista forense. Sin embargo la artista también necesita disponer de una base o modelo craneal sobre la que trabajar. 
2. I.3.- Realización del modelo craneal: Con esta tercera fase termina la fase antropológico forense de la aproximación facial. El modelo craneal sobre el que va a trabajar la artista puede hacerse obteniendo un negativo con alginato para después generar el positivo con escayola. Esta es la técnica que se sigue en la Universidad de Dundee (Escocia). No obstante tratándose de esqueletos de elevado valor cultural pensamos no practicar esta técnica ante el riesgo de poder generar desperfectos en algunos de los delicados huesos faciales. Por ello decidimos generar un prototipo plástico mediante la técnica llamada estereolitografía. Se trata de una moderna técnica que en algunos lugares recibe también el nombre de 'fotocopias en 3D' y que partiendo de imágenes digitalizadas en formato stl u otros, puede generar diversos prototipos según el tamaño de la máquina generadora. En nuestro caso hemos trabajado con imágenes en formato DICOM (Fig. 8). Este formato de imágenes (habitual en Radiología Médica) nos lo proporciona un Scanner Helicoidal convencional de 8 cortes, al que nosotros hemos aumentado la resolución generando un corte radiológico cada $0,625 \mathrm{~mm}$. De este modo el Scanner proporciona de cada cráneo más de 600 imágenes en formato DICOM que se envían a la empresa que fabrica el prototipo. El modelo del cráneo así obtenido es una réplica métricamente igual al original (Fig. 9) fabricado en un material lo suficientemente duro como para sostener la escultura que elaborará la artista forense, la polirresina.

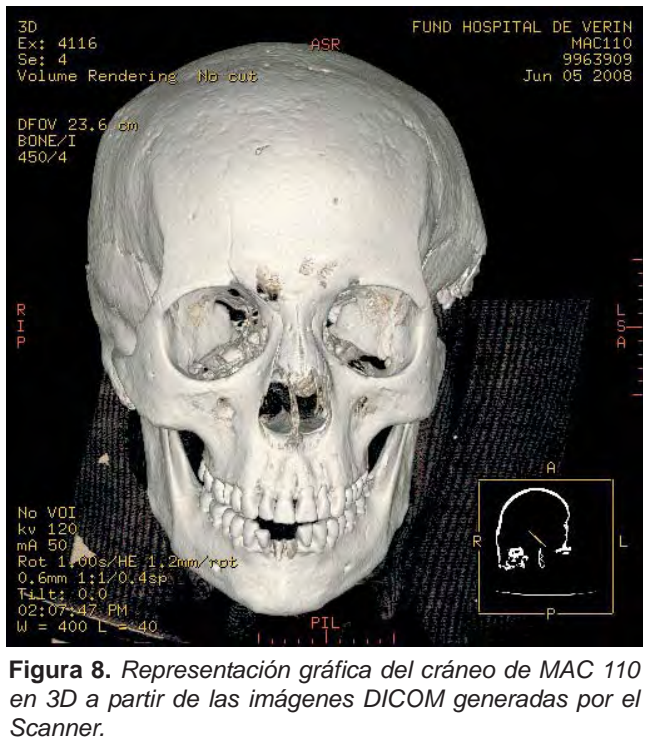

Una vez obtenidos el croquis antropológico y el modelo en polirresina ambos se pasan a la artista forense para iniciar la fase artística.

\section{2.- Fase artística forense:}

En esta fase es al Artista Forense al que le corresponde dirigir el proceso guiado por sus cualidades personales, conocimientos técnicos y experiencia. El antropólogo forense no deja de participar en esta fase pues se hace indispensable el contínuo contraste de opiniones en cada una de las siguientes fases a fin de lograr un trabajo que sea realmente una verdadera fusión de ciencia y arte con el mayor grado de precisión posible que permita aportar la técnica. 


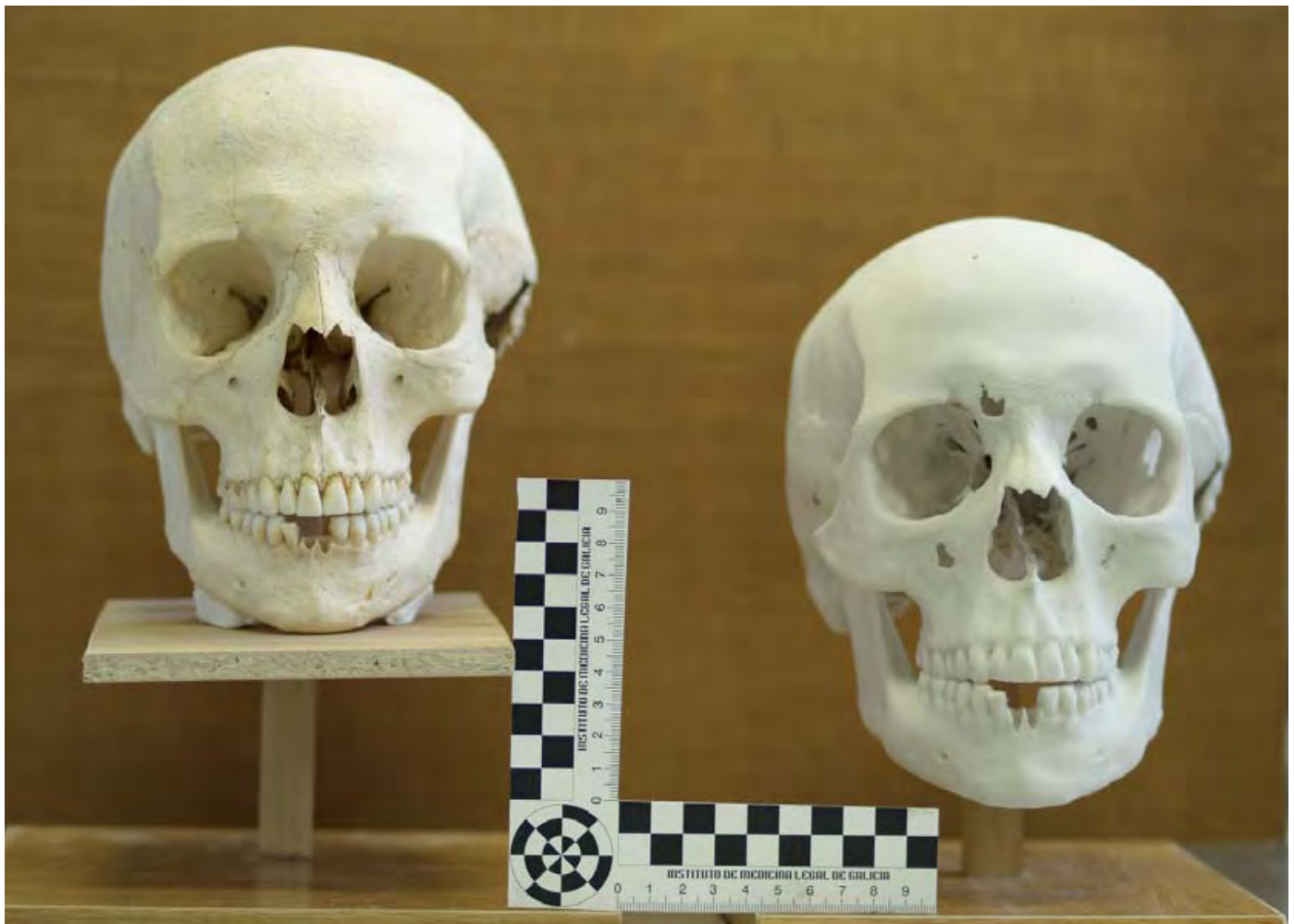

Figura 9. A la izquierda el cráneo original. A la derecha se observa su réplica en polirresina.

2.2. I.- Elaboración de propuestas 2D: Con la base del croquis antropológico la Artista Forense comenzó a realizar diversas propuestas en 2D. Es decir, croquis a lápiz de frente y perfil y dibujos más detallados hasta llegar a realizar la propuesta final de dibujo a color. Los aspec-

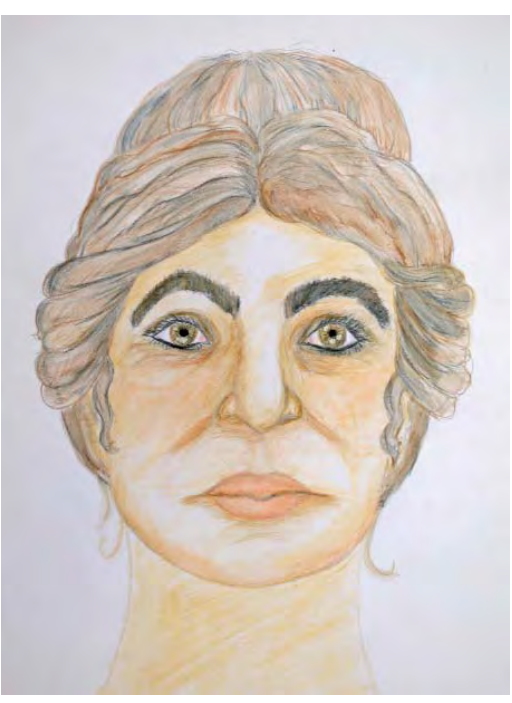

Figura 10. Propuesta final $2 D$ aceptada. tos estéticos fueron aportados por un Arqueólogo experto en el mundo romano y ayudaron a diseñar el pelo y el ajuar de nuestros casos. Todas las propuestas se dibujaron tomando como base el croquis antropológico proporcionado y sometiendo a contradicción aquellos aspectos morfológicos sobre los que se generaran dudas. La propuesta final 2D aceptada sirvió a la Artista Forense como guía de trabajo durante la parte escultórica del proceso (Fig. 10).

2.2.2.- Realización de la escultura: Disponiendo de una guía 2D, del prototipo en polirresina del cráneo y de todos los datos proporcionados por el croquis antropológico la Artista Forense trabaja directamente sobre la réplica del cráneo. En primer lugar posiciona el prototipo según el plano de Frankfurt y lo fija para trabajar con él siempre en la misma posición. A continuación corta los 52 tacos 
plásticos correspondientes de las profundidades de partes blandas señalados en el croquis que más adelante servirán de guía para la aposición de partes blandas (Fig. I I).

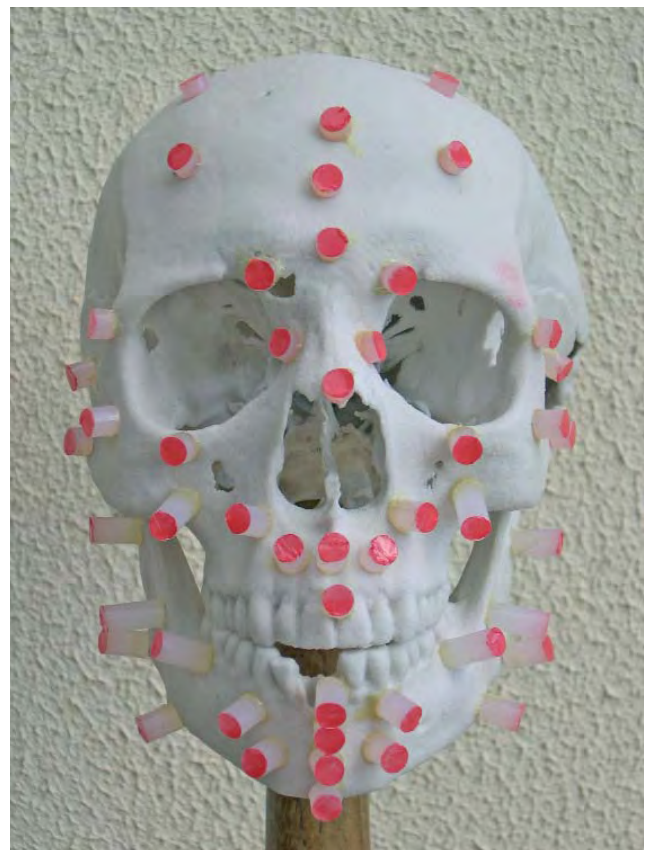

Figura 11. Disposición de los tacos plásticos de las profundidades de partes blandas.

La escultura pasa por diversas fases hasta la propuesta final de acabado. En este trabajo presentamos algunas fotografías de este proceso que creemos ilustra mejor el método seguido (Figs. 12 y 13).

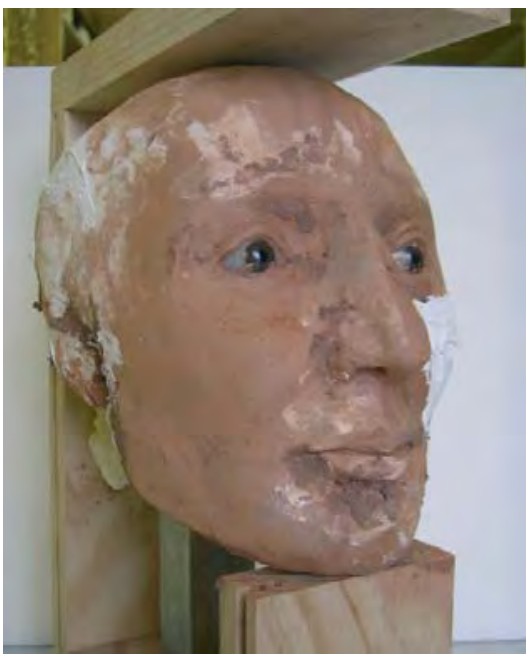

Figura 12. Fase intermedia del trabajo escultórico.

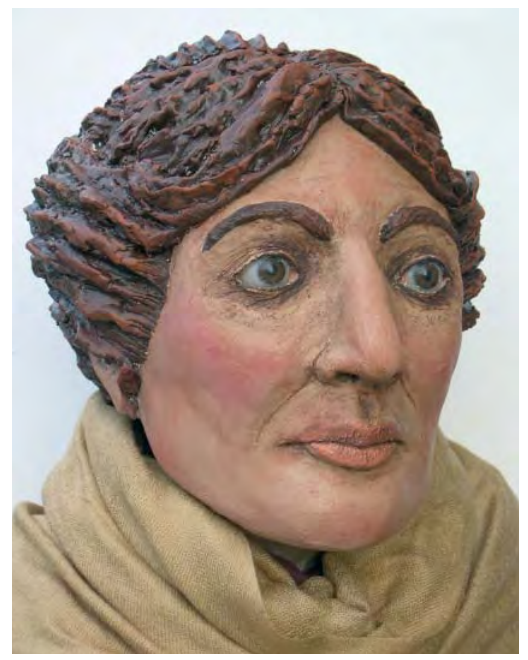

Figura 13. Primera propuesta de acabado final. 
2.2.3.- Decisión final: Se toma tras la valoración de diferentes propuestas de terminación. Una vez conocido el método de aproximación facial pasamos a continuación a explicar el método empleado en la aplicación de ésta técnica a la identificación humana en un caso concreto de nuestro laboratorio.

En este caso no disponíamos de muestra indubitada alguna con la que poder realizar algún tipo de estudio genético forense. El cadáver no había sido reclamado por nadie y no constaba denunciada la desaparición de nadie. Por ello nos propusimos generar varios dibujos de posibles personas aplicando algunas de las fases que acabamos de explicar. Para ello seguimos los siguientes pasos:

\section{$\left.1^{\circ}\right)$ FASE ANTROPOLÓGICO FORENSE:}

Esta fase como en el caso anterior se inicia por el estudio previo de todos aquellos datos que contribuyen a reconstruir la identidad de la persona que buscamos. Determinamos sexo, edad, talla y origen ancestral. Estudiamos todos aquellos datos que los restos humanos nos puedan proporcionar empleando todas las técnicas apropiadas al caso (radiología, toxicología, etc). Se obtienen de los datos policiales todos aquellos datos de interés al caso relativos a las circunstancias de la muerte. Se realiza comparación radiológica con dos casos dubitados.

En segundo lugar realizamos un croquis antropológico adaptado al caso que como se ve en la fotografia I contaba con algunas partes blandas carbonizadas de forma incompleta. Este croquis trató de señalar todos aquellos aspectos que pudieran ser de interés identificativo. En este caso el escaso número de dientes en la zona visible de la boca pudiera constituir un importante elemento de valoración para el reconocimiento de ésta persona (Fig. 14).

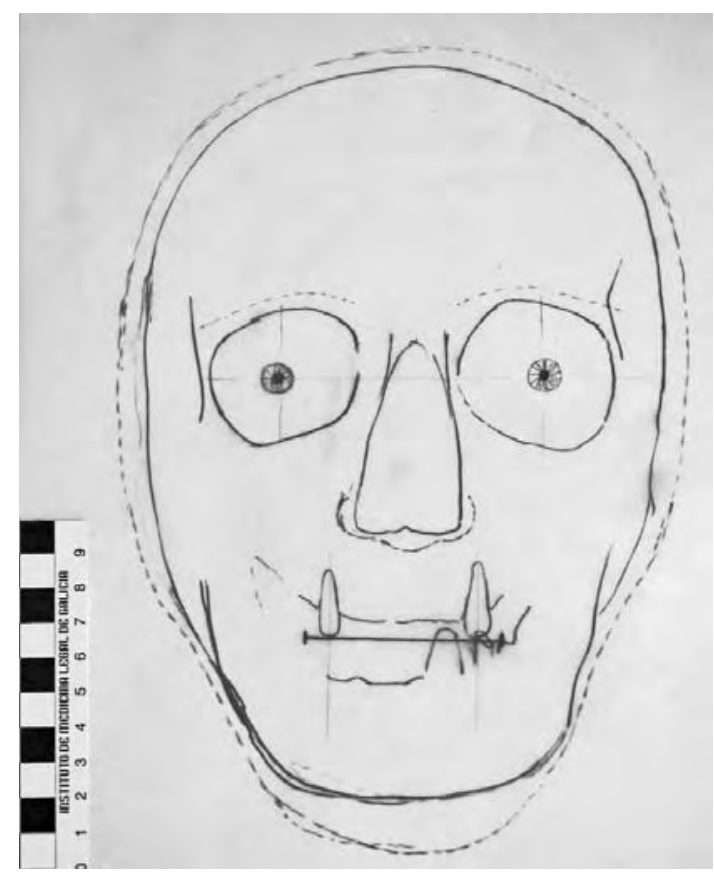

Figura 14. Croquis antropológico generado a partir de la Figura 4. 


\section{$2^{\circ}$ ) FASE ARTÍSTICA:}

Para terminar, el croquis antropológico se pasa a estudio a la Artista Forense quien realiza diversas propuestas en 2D atendiendo a todos los datos recabados (Figs. 22 y 23) según los mismos métodos antes explicados.

\section{RESULTADOS:}

I.- RELATIVOS A LA APROXIMACIÓN FACIAL:

El estudio antropológico forense de los tres esqueletos de época romana hallados en la ciudad de A Coruña ha permitido conocer los datos que se incorporan en la Tabla I. Son de destacar la presencia en MAC I I 0 de lesiones osteogénicas y osteolíticas en ambas tibias. Estas lesiones son compatibles con focos de osteomielitis y también con lesiones metastásicas carcinomatosas (Fig. 15). Destacamos también en MAC 108 la presencia de Criba Orbitalia lesión asociada a patologías anemizantes (Fig. 16) y osteonecrosis del pubis (Fig. 17). En MAC 44 I 4 hemos hallado importante foco de osteitis maxilar (Fig. 18), con sinusitis maxilar crónica y fistulizacion a través del paladar.

El resultado de la aproximación facial es el que se representa en las Figs. 19, 20 y 21. En el caso de MAC 108 por encargo del Ayuntamiento de A Coruña el busto se dejó sin terminar para poder observar el proceso de aproximación facial.

TABLA 1: Síntesis de los resultados antropológicos.

\begin{tabular}{|l|l|l|c|l|l|}
\hline Esqueleto & Sexo & Edad & Talla & O.Ancestral & \multicolumn{1}{|c|}{ Patologia detectada } \\
\hline MAC 108 & Mujer & $18-20$ & 155 & Caucasoide & $\begin{array}{l}\text { Criba orbitalia } \\
\text { Osteonecrosis pubis }\end{array}$ \\
\hline MAC 110 & Mujer & $20-25$ & 160 & Caucasoide & $\begin{array}{l}\text { Lineas de Harris } \\
\text { Osteomielitis tibias-Metástasis (?) }\end{array}$ \\
\hline MAC 4414 & Mujer & $30-35$ & 145 & Caucasoide & $\begin{array}{l}\text { E.Periodontal avanzada } \\
\text { Osteítis maxilar inferior. } \\
\text { Sinusitis maxilar con fistulización. } \\
\text { Hipotrofia ESI.TCE antiguo. }\end{array}$ \\
\hline
\end{tabular}

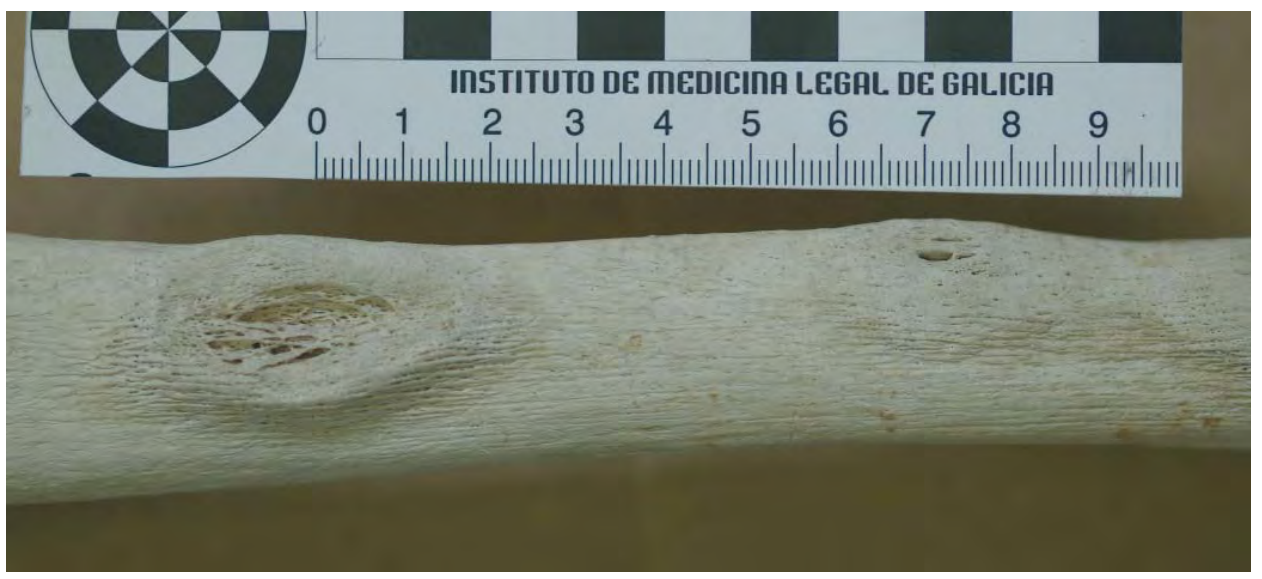

Figura 15. Lesiones en la tibia izquierda de MAC 110 compatibles con focos de ostemielitis y también con metástasis carcinomatosas. 


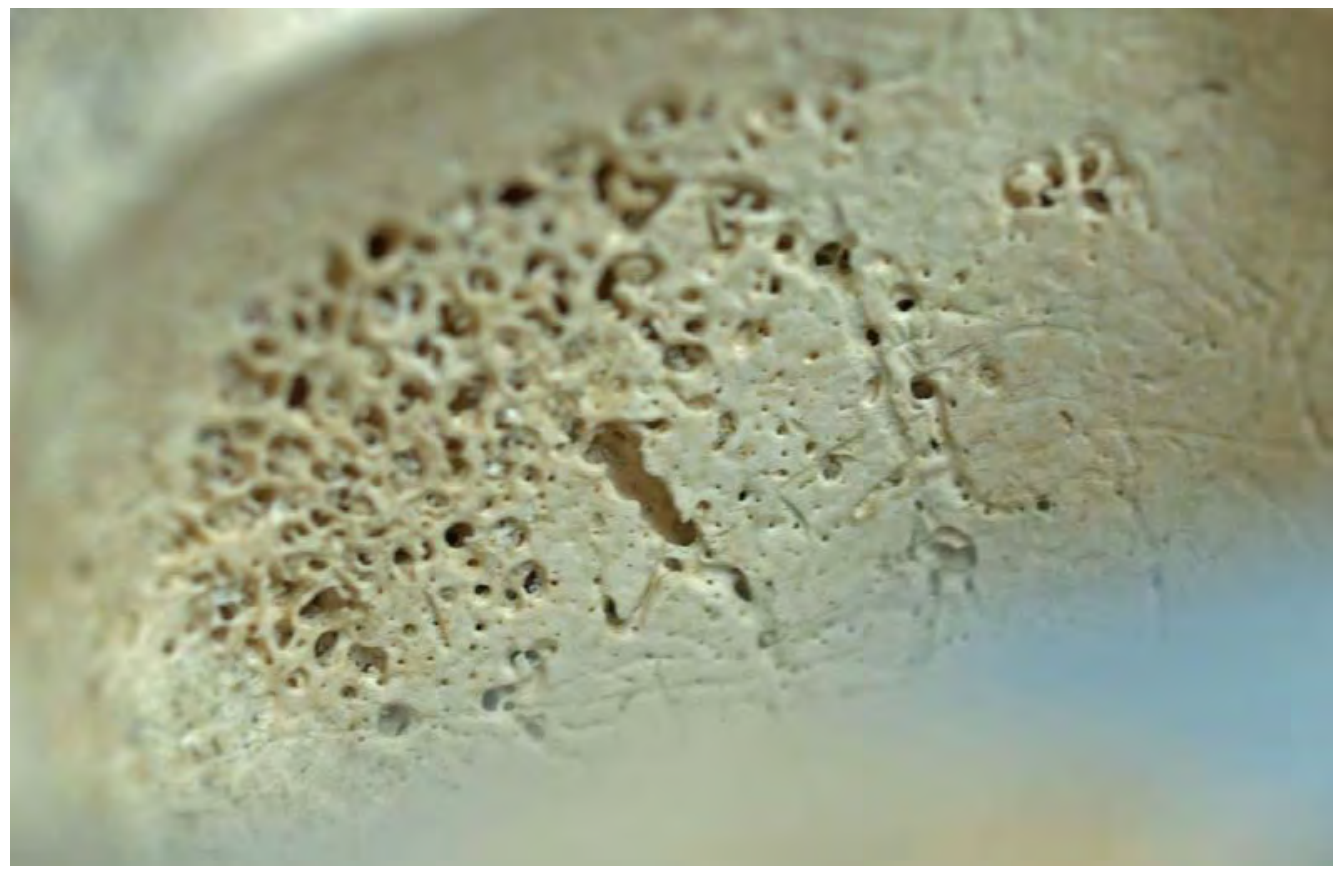

Figura 16. Criba orbitalia, del techo de la órbita derecha de MAC 108.

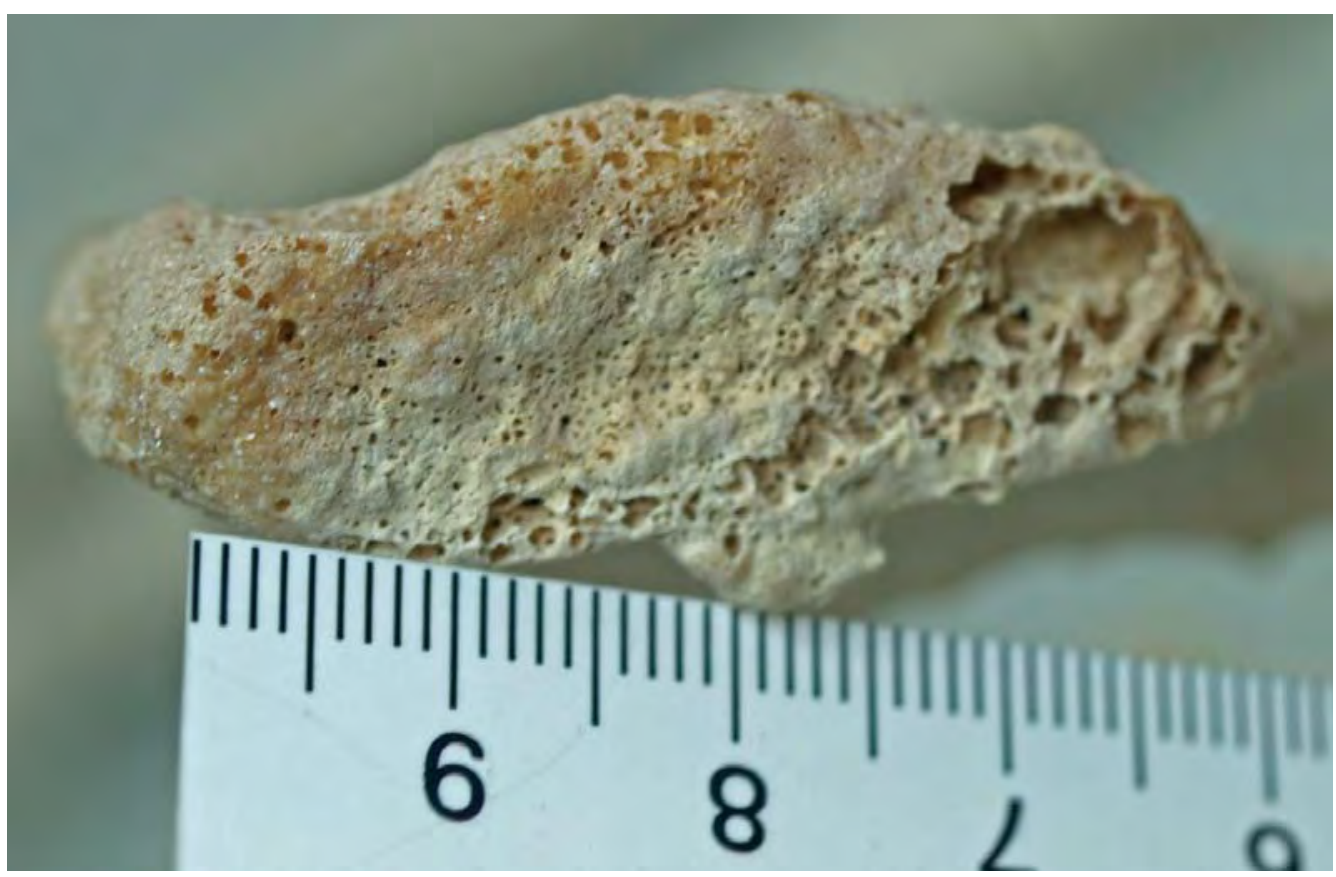

Figura 17. Osteonecrosis del pubis de MAC 108. 


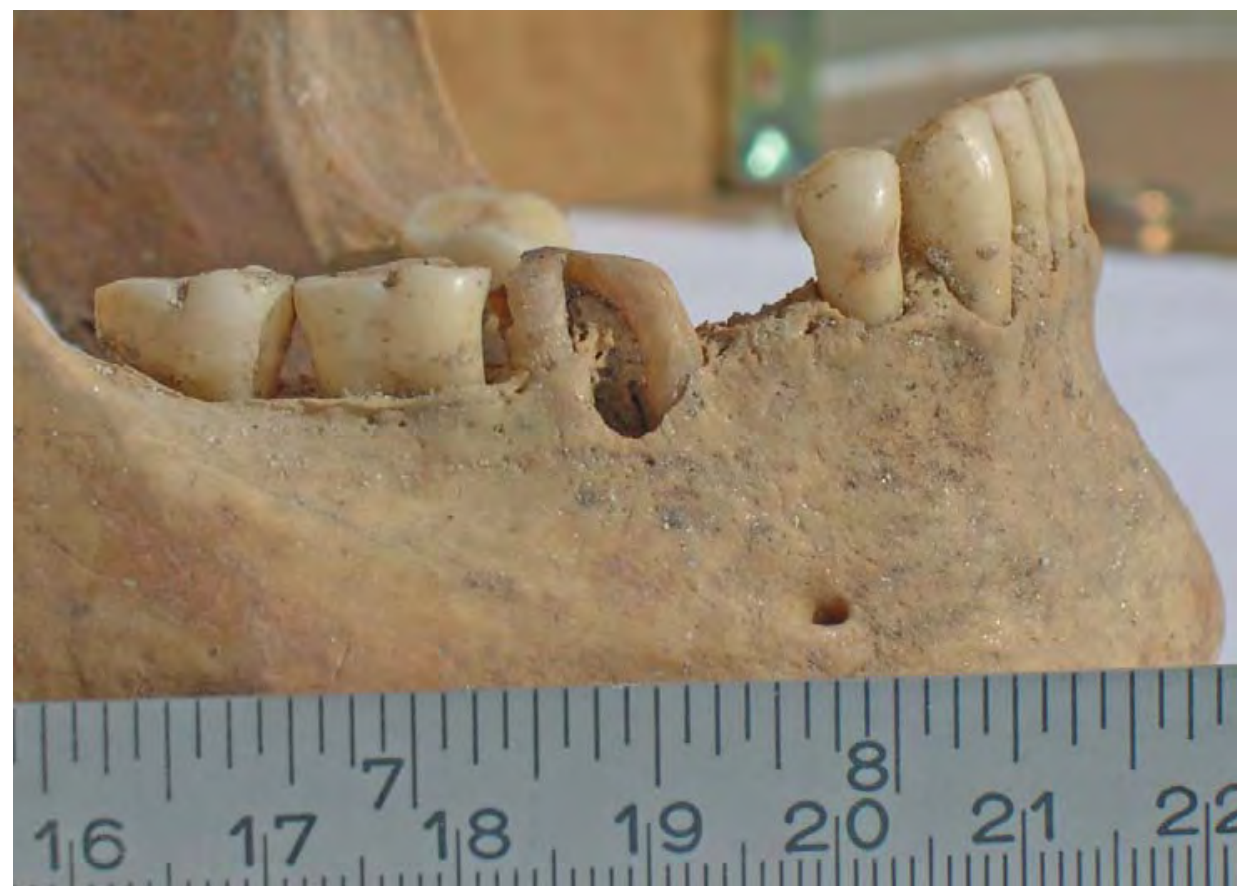

Figura 18. Osteitis maxilar importante en mandibula de MAC 4414.

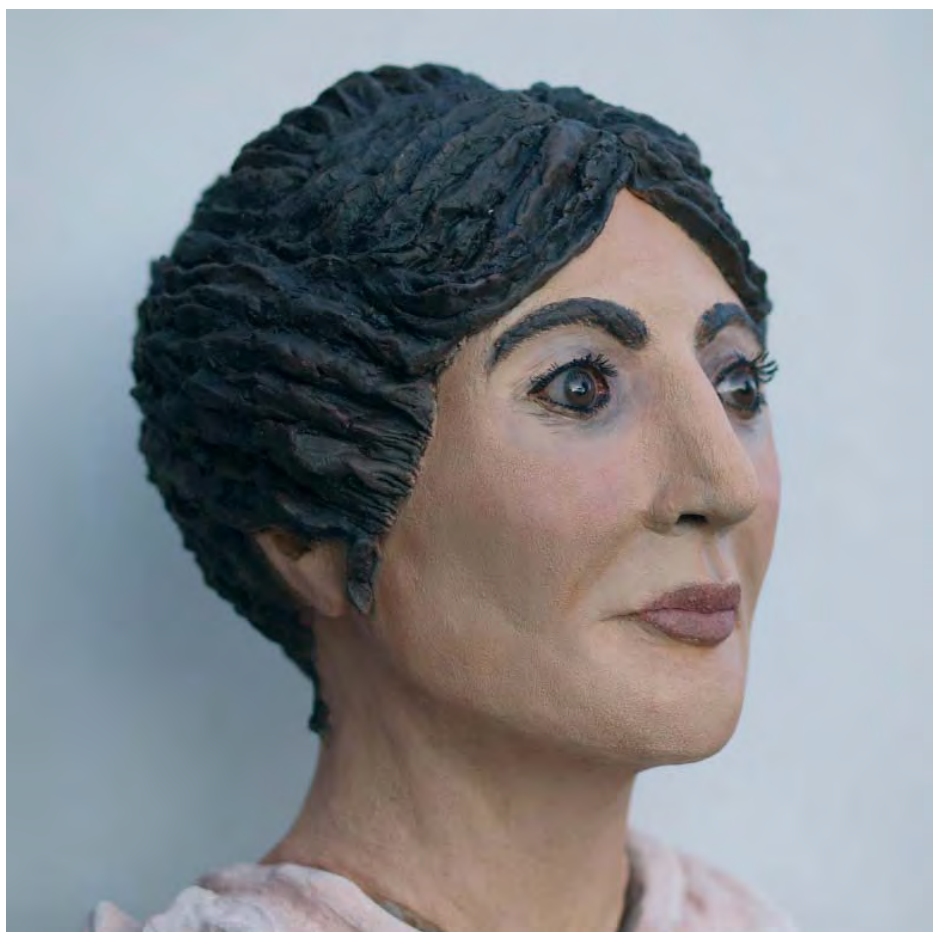

Figura 19. Propuesta final aceptada MAC 110. 


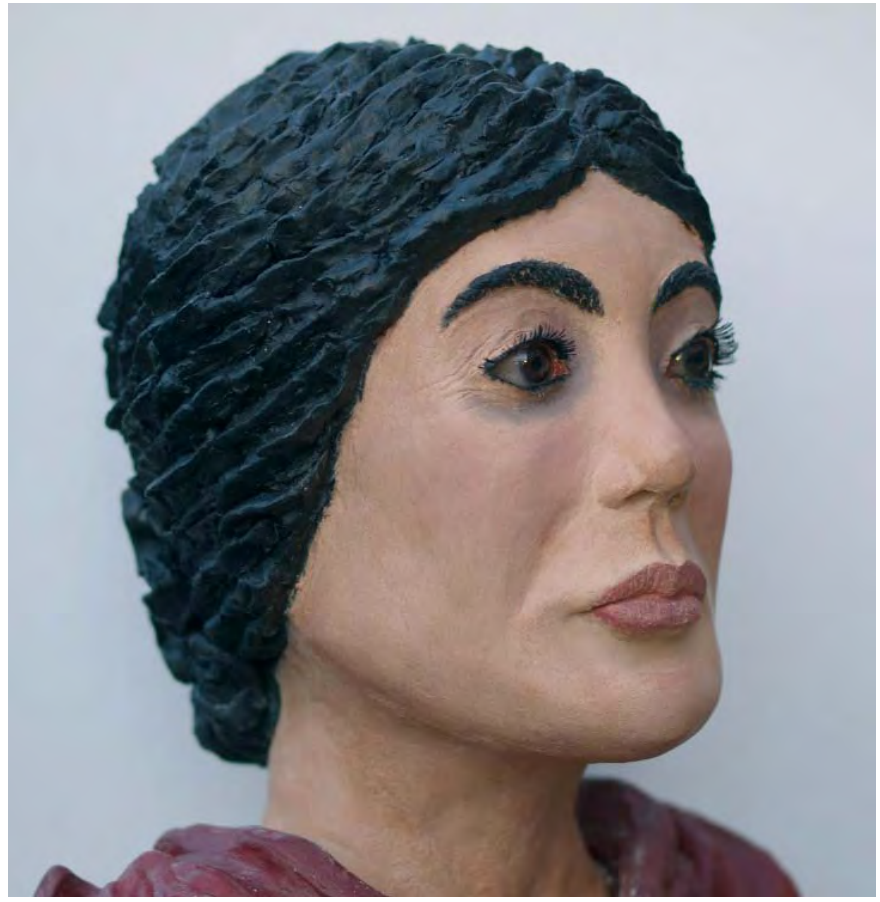

Figura 20. Propuesta final aceptada de MAC 4414.

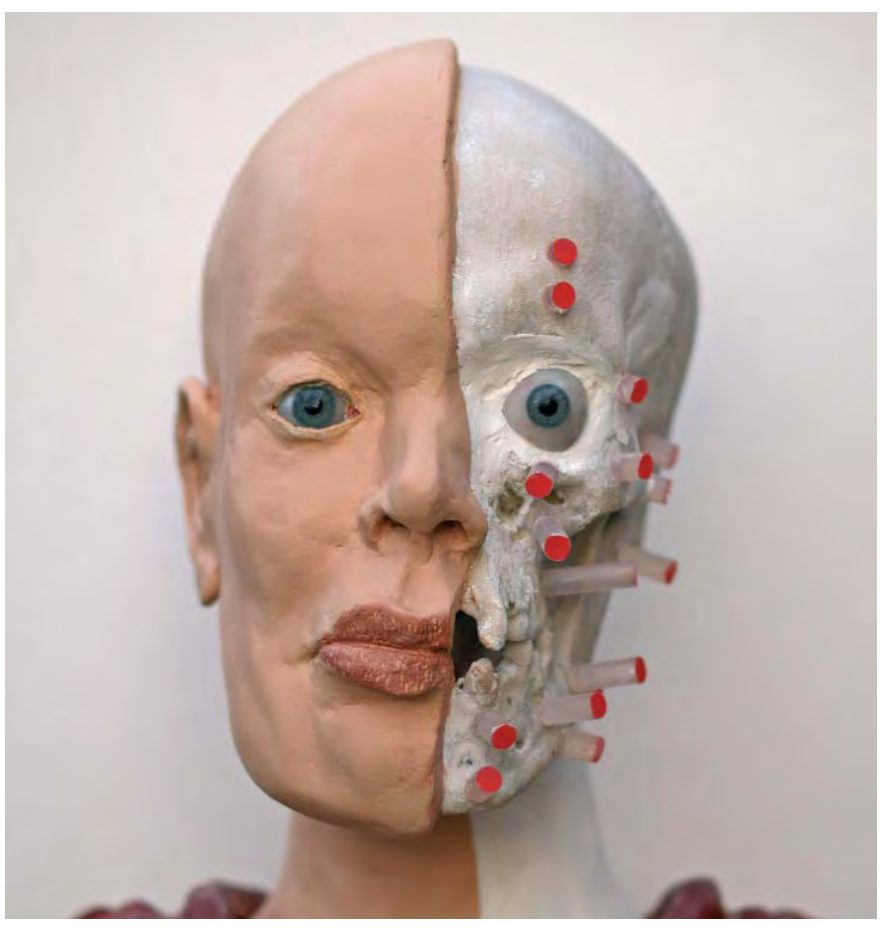

Figura 21. Propuesta final aceptada de MAC 108. 


\section{2.- RELATIVOS A LA IDENTIFICACIÓN HUMANA:}

El cadáver carbonizado pertenecía a un varón, adulto, de edad media (25-45 años) y de talla en torno a $160-165 \mathrm{~cm}$. Los datos relativos a las circunstancias de la muerte referidos por la policía confirman que el cadáver apareció en una caseta abandonada, que se quemó unos meses atrás y que era frecuentada por toxicómanos e indigentes. El cadáver presentaba una avanzada enfermedad periodontal con pérdida antemortem de casi todos los dientes visibles con la boca medio abierta.

Generamos tres imágenes posibles de la persona desaparecida y dos de éstas se difundieron a los medios de comunicación locales. La respuesta ciudadana aportó el nombre de un transeúnte que hacía meses no se le veía. La comparación radiológica y el estudio de la historia clínica permitió excluirlo sin género de duda. La Guardia Civil de una provincia próxima teniendo conocimiento de la noticia aportaron los datos de una persona desaparecida meses atrás. La comparación de las radiografías del seno frontal permitió excluirlo también. No se han aportado por el momento más posibles candidatos.
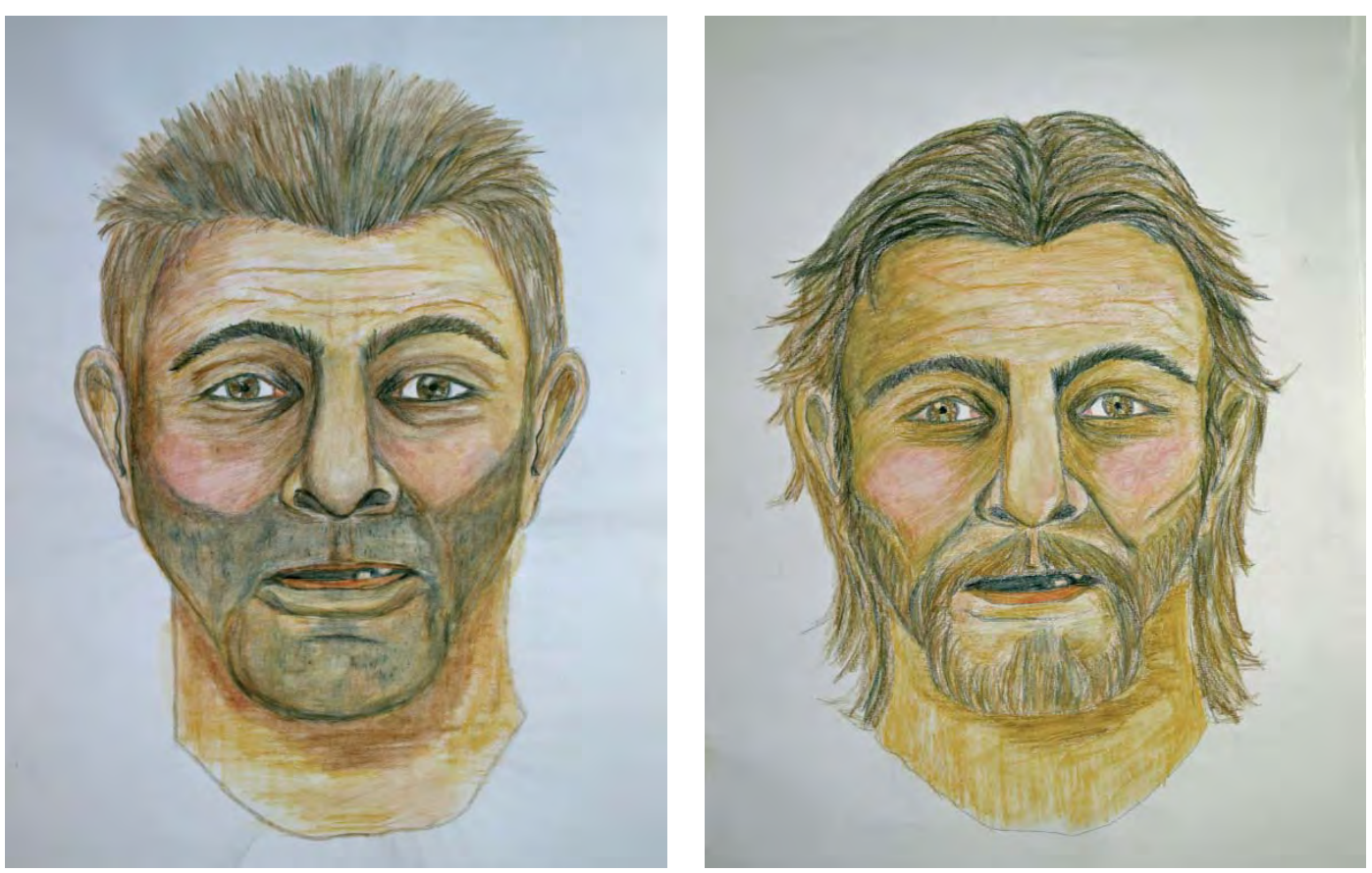

Figuras 22 y 23: Aproximaciones faciales de la persona cuyo cadáver apareció carbonizado.

\section{CONCLUSIONES:}

I.- Consideramos que las técnicas denominadas de 'reconstrucción facial' contienen un número relativamente elevado de imprecisiones en todas las fases del proceso y tanto en técnicas artísticas como asistidas por ordenador. Estas imprecisiones son debidas esencialmente a que existen muchos elementos de reconocimiento facial que no son deducibles desde la estructura ósea como por ejemplo la forma y el color del pelo, la morfología del pabellón auricular, la distribución concreta y personal del tejido celular subcutáneo, la existencia, distribución y morfología concreta de las arrugas (textura de la piel), etc. Todos éstos elementos es necesario deducirlos con insuficientes fundamentos científicos utilicemos la técnica que utilicemos. 
Técnicas artísticas y asistidas por ordenador tienen ventajas y desventajas tanto absolutas como relativas. Las técnicas asistidas por ordenador tienen la ventaja de poder generar en poco tiempo una propuesta de rostro, sin embargo hasta el momento no consiguen transmitir al modelo la viveza que dan las técnicas artísticas. En nuestra opinión no es tan importante elegir una u otra técnica, lo realmente importante es experimentar lo más posible con la técnica que se elija para dominarla y reducir al mínimo posible las imprecisiones que se puedan generar.

Creemos por lo tanto que es preferible referirse a estas técnicas usando el término 'aproximación facial', siendo conscientes que nuestro trabajo podrá en el mejor de los casos acercarnos a conocer el rostro de una persona sin pretender obtener una fidedigna reproducción facial de la persona desaparecida.

2.- La técnica de aproximación facial tal y como la describimos en este trabajo es una técnica costosa porque requiere una elevada inversión económica y de tiempo, lo que en la práctica diaria no la hace útil en el ámbito forense. No obstante pensamos que pueden practicarse modificaciones que permitan -sin perder precisión- acortar los plazos temporales y reducir sustancialmente el costo del trabajo. Creemos posible realizar un busto por aproximación facial en unos 10- I 5 dias a un costo relativamente bajo. Por todo ello nuestro laboratorio no cierra esta línea de investigación, y proseguirá adquiriendo la experiencia necesaria que nos permita dar un servicio de calidad a la Administración de Justicia.

3.- Hemos comprobado que las limitaciones que presentan las técnicas de aproximación facial no suponen una absoluta descalificación de las mismas con fines forenses. Es más, creemos que el caso que presentamos muestra que éstas técnicas pueden ser la única herramienta que tengamos para identificar a una persona cuando la genética forense no tiene campo de actuación. Se trata de casos en los que no está denunciada la desaparición de nadie y/o no existe muestra indubitada con la que poder comparar. En el caso que mostramos valoramos la respuesta ciudadana como muy satisfactoria y aunque los resultados no nos han permitido afirmar la identidad, creemos que haber excluido a dos personas ha servido para dar un completo servicio a la Administración de Justicia y sobre todo para dar tranquilidad a dos familias.

\section{AGRADECIMIENTOS:}

Este trabajo es el fruto de la colaboración de un gran número de profesionales que han puesto su ilusión y su entusiasmo con una generosidad a la que hoy día no estamos acostumbrados. Deseo expresar desde aquí mi sincera gratitud a Benito López de Abajo, José Blanco Pampín, José Alfeirán, José Manuel Coello, Cruz Galindo, Enrique Pérez, todo el personal del Servicio de Radiología del Hospital Fundación Pública Verin, lago Martínez y Prudencio García. Deseo hacer una mención especial a la empresa LAISECA que donó de forma altruista las prótesis oculares utilizadas. Y por supuesto a Miguel y a Herminia que siempre están ahí. También a Vicente Boveda, por su ayuda en la revisión del texto en inglés.

\section{BIBLIOGRAFÍA:}

I. Metodología para elaborar reconstrucciones faciales empleando gráficos computerizados tridimensionales. Tesis Doctoral de Lorena Valencia Caballero. Director: Dr Dn Miguel C Botella López. Universidad de Granada. 2007.

2. Gerasimov MM. 1955. Vosstanovlenie lica po cerepu. Moskva: Izdat. Akademii Nauk SSSR.

3. Gerasimov MM . 197I. The face finder. New York: CRC Press.

4. Krogman WM 1962 The human skeleton in Forensic Medicine. Charles C. Thomas, Springfield.

5. Krogman WM, Iscan MY. 1986. The human skeleton in Forensic Medicine. Charles C. Thomas, Springfield.

6. Ubelaker, D. H. and G. O'Donnell (1992). "Computer-assisted facial reproduction." Journal of Forensic Sciences 37(I): 155162. 
7. Ubelaker, D. H. (1993). "Facial reconstruction." Journal of Forensic Sciences 37: 1442-1444.

8. Quatrehomme, G., S. Cotin, et al. (1997). "A fully three-dimensional method for facial reconstruction based on deformable models." Journal of Forensic Sciences 42(2): 649-652.

9. Rynn, C. and C. M. Wilkinson (2006). "Appraisal of traditional and recently proposed relationships between the hard and soft dimensions of the nose in profile." American Journal of Physical Anthropology 130: 364-373.

10. De Greef, S. and G. Willems (2005). "Three-dimensional craniofacial reconstruction in forensic identification: Latest progress and new tendencies in the 21st century." Journal of Forensic Sciences $50(\mathrm{I}): 12-17$.

II. www.CRANIOFACIALidentification.com.

12. Stephan, C. N. and R. S. Arthur (2006). "Assessing facial approximation accuracy: how do resemblance ratings of disparate faces compare to recognition tests?" Forensic Science International I59S: SI59-S163.
I3. Stephan, C. N. and P. L. Davidson (2008). "The Placement of the Human Eyeball and Canthi in Craniofacial Identification." Journal of Forensic Sciences 53: 612-619.

14. Stephan, C. N. (2002). "Facial Approximation: Falsification of globe projection guideline by exophthalmometry literature." Journal of Forensic Sciences 47(4): I-6.

15. Stephan, C. N. (2002). "Position of superciliare in relation to the lateral iris: Testing a suggested facial approximation guideline." Forensic Science International I30: 29-33.

16. Stephan, C. N. and M. Henneberg (2003). "Predicting mouth width from inter-canine width - A 75\% rule." Journal of Forensic Sciences 48(4): 725-727.

17. De Greef, S., P. Claes, et al. (2006). "Large-scale in-vivo Caucasian soft tissue thickness database for craniofacial reconstruction." Forensic Science International I59S: SI26-SI46. 